\title{
Ultrastructure of the buccal capsule in the adult female Anguillicoloides crassus (Nematoda: Anguillicolidae)
}

\author{
M. BRUŇANSKÁ ${ }^{1,2}$, H.-P. FAGERHOLM ${ }^{3}$, F. MORAVEC ${ }^{1}$, Z. VASILKOVÁ $^{2}$
}

${ }^{1}$ Institute of Parasitology, Biology Centre of the Academy of Sciences of the Czech Republic, Branišovská 31, 37005 České Budějovice, Czech Republic, E-mail: brunan@saske.sk; ${ }^{2}$ Parasitological Institute, Slovak Academy of Sciences, Hlinkova 3, 04001 Košice, Slovak Republic; ${ }^{3}$ Åbo Akademi University, Department of Biology, Laboratory of Aquatic Pathobiology, Artillergatan 6, BioCity, 20520 Åbo/Turku, Finland

\begin{abstract}
Summary
The fine structure of the buccal capsule of the adult female nematode Anguillicoloides crassus (Spirurina) was studied for the first time. Results are based on serial section (longitudinal and transverse) light and transmission electron microscopy. The buccal capsule of $A$. crassus is a cuticular-lined structure. It can be divided into three main parts: cheilostom, gymnostom and stegostom. The cheilostom is the anterior region of the buccal capsule with the cuticular lining continuous with the body wall cuticle and underlain by epidermal syncytia. The gymnostom is a cuticular region with portions of it very electron dense and underlain by arcade syncytia. A dense circumoral cylinder together with the circumpharyngeal ring represent the prominent characters of the gymnostom. The stegostom is formed by anterior pharyngeal cuticle underlain by muscular radial cells and epithelial marginal cells. The cephalic cuticle of A. crassus makes a direct contact with the pharyngeal cuticle at the base of the circumoral cylinder, within a circumpharyngeal ring containing projections of pharyngeal muscular and marginal cells. The circumoral cylinder, circumpharyngeal ring and pharynx are connected to the body epidermis by junctional complexes. The buccal capsule includes occasionally 3 projections of the pharynx evidently observed in serial cross sections. These ultrastructural characters may provide useful data for comparative, functional as well as evolutionary studies within the Chromadorea.
\end{abstract}

Keywords: Ultrastructure; Anguillicoloides crassus; Buccal capsule

\section{Introduction}

The swimmbladder nematode Anguillicoloides crassus (Kuwahara, Niimi et Itagaki, 1974) is a parasite specific to freshwater eels (Anguilla spp.) (Moravec, 2006). This East Asian parasite has greatly attracted interest after colonizing
Europe, Africa and North America (Moravec, 1992; Kennedy et al., 1997; Kirk, 2003; Maítlo et al., 2005; Knopf, 2006; Taraschewski, 2006; Sasal, 2008). A. crassus has spread mainly due to its large egg production and wide range of intermediate and paratenic hosts (Bauer, 1998; Moravec \& Škoríková, 1998). Eels are damaged both by larvae, which live in the tissue of the swimbladder, and adults or juveniles, sucking host blood (Didžiulis, 2006). The question, whether pathological changes in colonized host are caused only by the blood-sucking activity of the adult parasite remains controversial (Taraschewski, 2006). It is noteworthy that lesions induced by $A$. crassus to the host swimbladder epithelium correspond to the size of the mouth of the adult nematode (Taraschewski et al., 1987).

Little is known about the fine structure of Anguillicoloides. Available observations deal with the body wall (Lamah et al., 1990; Würtz \& Taraschewski, 2000; Taraschewski et al., 2005) and pharynx (Bruňanská et al., 2007). Thus there is a gap in our knowledge on the ultrastructure of the buccal capsule ( $=$ the region between the pharynx and the mouth) of Anguillicoloides, a structure which may play an important role in the infestation process.

The current study aims, therefore, to give a detailed description of the microanatomy of the buccal capsule of $A$. crassus based on the adult female worm, and also provides a base for a better understanding of the function of digestive system of a blood-feeding nematode. The study will further expand the knowledge on the range of variation of the cephalic region in spirurine nematodes, as well as possible use of ultrastructural characters of the buccal capsule in a phylogenetic context.

\section{Material and methods}

Adult female Anguillicoloides crassus were recovered from the swimbladder of European eels Anguilla anguilla (L.) in the Mácha Lake fish pond in the Czech Republic, 
and/or from the northern Baltic Sea in Lemland Åland, Finland. Live worms were rinsed in saline solution; their anterior regions containing buccal capsule were then cut off and fixed in $2.5 \%$ glutaraldehyde in $0.1 \mathrm{M}$ cacodylate/phosphate buffer ( $\mathrm{pH} \mathrm{7.4)} \mathrm{for} 20 \mathrm{hr}$ at $4{ }^{\circ} \mathrm{C}$. The samples were post-fixed in $1 \% \mathrm{OsO}_{4}$ in $0.1 \mathrm{M}$ cacodylate buffer for $1 \mathrm{hr}$ at $4{ }^{\circ} \mathrm{C}$, dehydrated in a graded series of alcohol or acetone, and embedded in Epon.

Anterior regions of 2 worms were oriented for longitudinal sectioning and 3 worms for cross sectioning. Semithin sections for light microscopy of the buccal capsule were
For scanning electron microscopy (SEM), the material was fixed using the above procedure. The difference was that the material dehydrated in $100 \%$ acetone was transferred to a critical point apparatus where it was dried at increasing pressure and temperature after an initial replacement of acetone with liquid $\mathrm{CO}_{2}$. Mounted specimens were examined in a Zeiss SEM.

The nomenclature used for the buccal capsule structures largely follows the terminology introduced in De Ley et al. (1995).

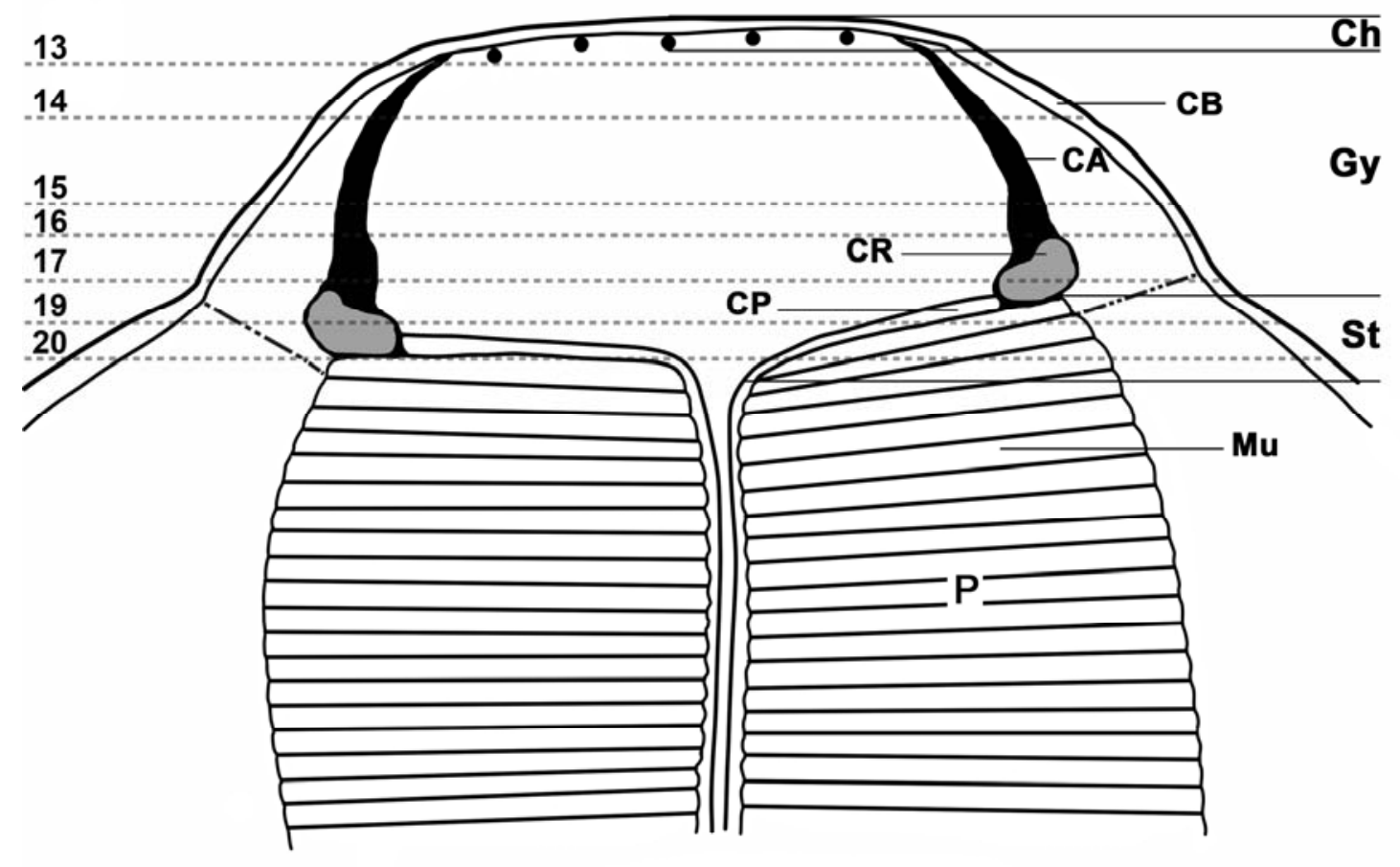

Fig. 1. Diagrammatic longitudinal representation of the adult $A$. crassus buccal capsule through subventral sectors as reconstructed from transmission electron microscopy (TEM) serial sections (both longitudinal and transverse). Pharynx (P) is relaxed. Numbers to the left show the relative positions of the adequate electron micrographs. $\mathrm{Ch}$ - cheilostom, $\mathrm{Gy}$ - gymnostom, $\mathrm{St}-$ stegostom, $\mathrm{CA}-\mathrm{circumoral}$ cylinder, $\mathrm{CB}-$ body cuticle, $\mathrm{CP}$ - pharyngeal cuticle, $\mathrm{CR}$ - circumpharyngeal ring, $\mathrm{Mu}-$ muscle cells. $\mathrm{Bar}=25 \mu \mathrm{m}$

cut on a Reichert ultramicrotome and stained with methylene or toluidine blue; 25 series of longitudinal sections of 1 worm were prepared, each consisting of 2 longitudinal semithin sections and 8 ultrathin sections. Each group of sections was followed by cutting off tissue $10 \mu \mathrm{m}$ thick. The stained semithin sections were observed and photographed using light microscopy. The transverse serial semithin and ultrathin sections were made starting from the anteriormost part of the buccal capsule. Ultrathin sections (60 nm thick) were cut using a Leica Ultracut UCT ultramicrotome, stained with uranyl acetate and lead citrate, and examined in a JEOL JEM 100XS and JEOL 1010 transmission electron microscopes (TEM) operating at 60 and $80 \mathrm{kV}$, respectively.

\section{Results}

The buccal capsule of the adult female Anguillicoloides crassus is small ( $24-27 \mu \mathrm{m}$ length, $55-62 \mu \mathrm{m}$ width), and lined most anteriorly by a rim with one row of some 26 circumoral teeth (Figs. 1, 2, 3). It can be divided into three main parts: cheilostom, gymnostom and stegostom (Fig. 1).

The cheilostom is the anterior region of the buccal capsule with the cuticular lining continuous with the body wall cuticle and underlain by hypodermal syncytia. It includes circumoral teeth $(4-5 \mu \mathrm{m}$ in length) which are partly overlapped by the cephalic cuticle (Fig. 2), or protrude into the lumen of the buccal capsule (Figs. 3, 4). The mouth 
aperture is small $(20-25 \mu \mathrm{m}$ in diameter) and circular. Four big cephalic papillae (two dorsolateral and two ventrolateral) together with the two small lateral amphids are present in the close vicinity of the buccal capsule.

The cuticle of the cheilostom has a prominent middle zone of lower electron density (Figs. 5, 6). The middle zone is delimited by external and internal zones. The external zone consists of a triple-layered lamella which is composed of two opaque peripheral layers and a middle light layer. The anteriormost part of the circumoral cylinder is overlapped by cuticular flaps $(1.5-2 \mu \mathrm{m}$ long) projecting into the buccal cavity, and well visible in the longitudinal sections through the middle part of the buccal cavity (Figs. 6, 7).

The gymnostom is a cuticular region with portions of it very electron dense and underlain by arcade syncytia. The serial semi- and ultrathin longitudinal and cross sections of the head region of $A$. crassus revealed the presence of the prominent circumoral cylinder within the buccal capsule (Figs. 4, 5). The anteriormost extremity of this cylinder forms individual circumoral teeth (Figs. $5-7$ ). Junctional complexes demark the boundary of the arcade syncytia of the gymnostom (Figs. 8, 9).

The stegostom is represented by anterior pharyngeal cuticle underlain by muscular radial cells and epithelial mar-
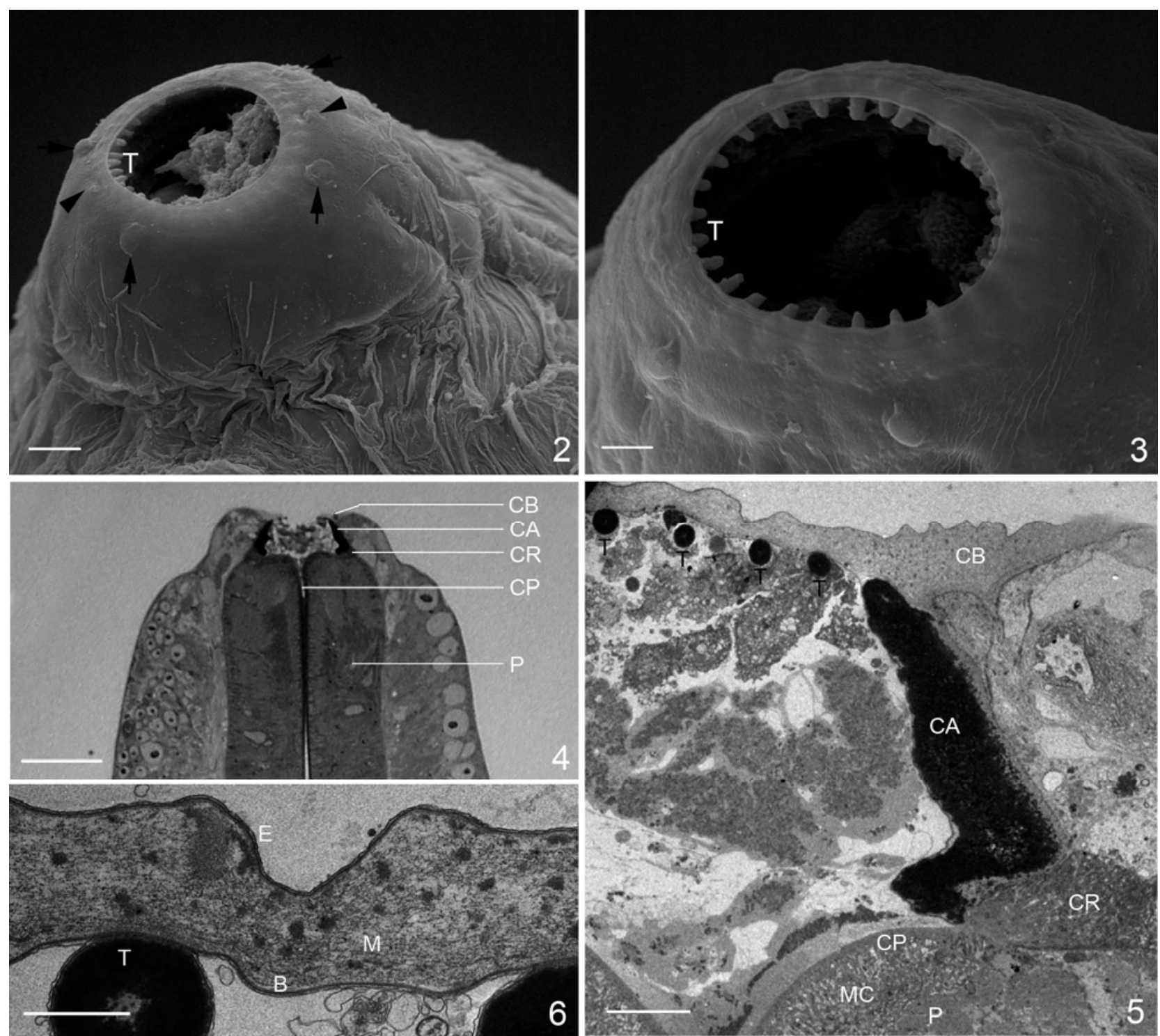

Fig. 2. Scanning electron micrograph (SEM) of the head of adult female Anguillicoloides crassus. Mouth opening with circumoral teeth (T) (some not visible), 4 dorsolateral cephalic papillae (arrows), and 2 lateral amphids (arrowheads). Note relatively smouth cephalic cuticle and the wrinkled body cuticle. $\mathrm{Bar}=10 \mu \mathrm{m} ;$ Fig. 3 . SEM of the mouth opening with the marked circumoral teeth $(\mathrm{T})$. Bar $=4 \mu \mathrm{m} ;$ Fig. 4 . Longitudinal semithin section (ventrodorsal view) through the skirt of the buccal capsule. CB - body cuticle, CP-pharyngeal cuticle, $\mathrm{CA}$ - circumoral cylinder, $\mathrm{CR}$ - circumpharyngeal ring, $\mathrm{P}$ - pharynx. Bar $=50 \mu \mathrm{m}$; Fig. 5. Longitudinal ultrathin section following the region shown in Fig. 4. CB - body cuticle, $\mathrm{CP}$ - pharyngeal cuticle, $\mathrm{CA}$ - circumoral cylinder, $\mathrm{CR}$ - circumpharyngeal ring,

$\mathrm{MC}-$ marginal cells, $\mathrm{T}$ - circumoral teeth. Bar $=5 \mu \mathrm{m}$; Fig. 6 . Detail of the cuticle in the cheilostom of $A$. crassus (TEM). B-inner zone, $\mathrm{E}-$ external zone, $\mathrm{M}-$ middle zone, $\mathrm{T}-$ circumoral teeth. $\mathrm{Bar}=1 \mu \mathrm{m}$. 

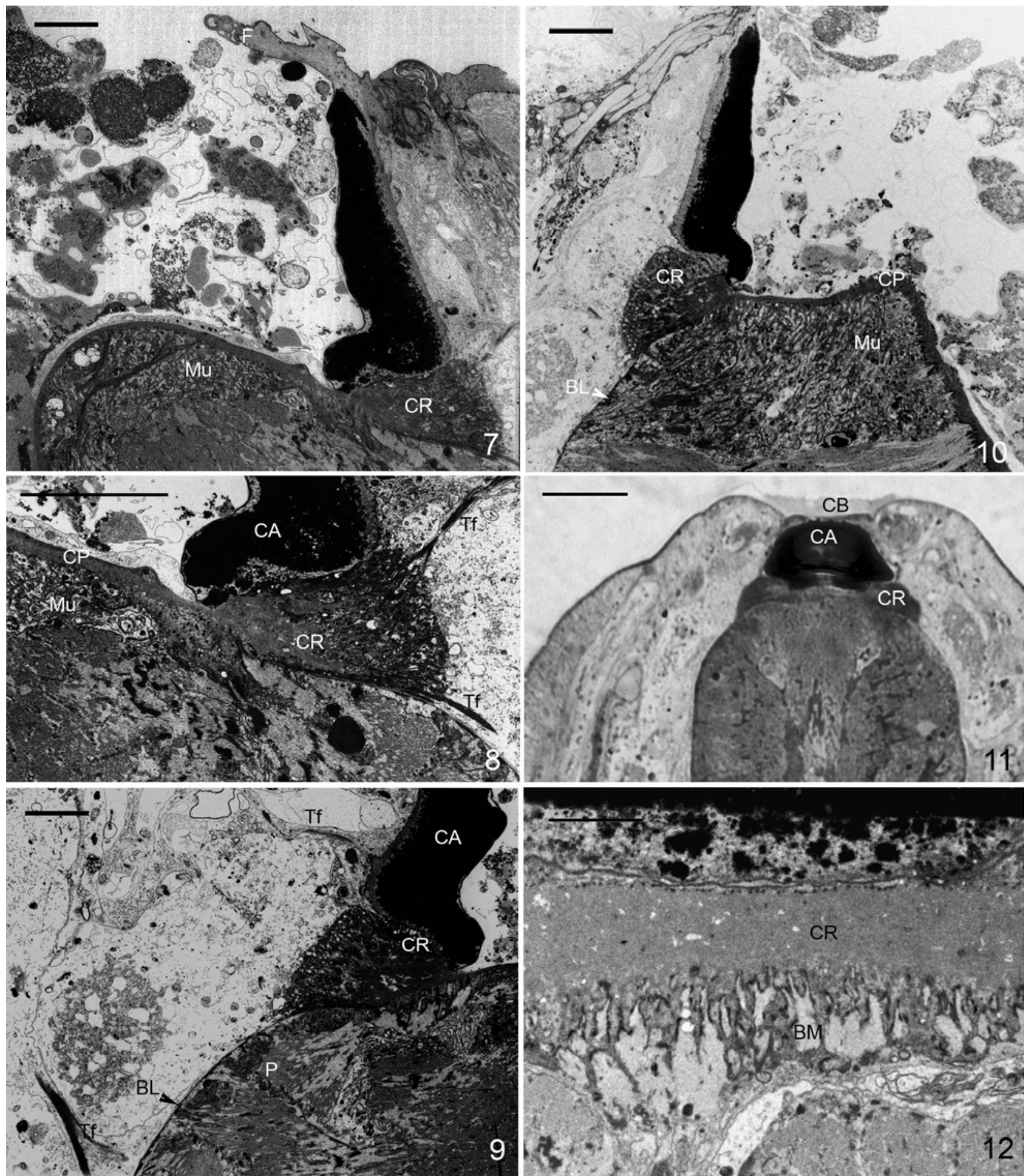

Fig. 7. Serial longitudinal section (ventrodorsally continuation of the level seen in Fig. 4), showing cuticular flaps (F) extending into the cheilostom. Note components of muscle cells $(\mathrm{Mu})$ in the anterior pharynx as well as in circumpharyngeal ring $(\mathrm{CR})$. Bar $=5 \mu \mathrm{m}$; Fig. 8 . A detail of the circumpharyngeal ring (CR). Note pharyngeal cuticle (CP) and anteriormost part of muscle cells $(\mathrm{Mu})$ protruding underneath the circumoral cylinder (CA). Tf - junctional complexes. Bar $=10 \mu \mathrm{m}$; Fig. 9. Junctional complexes (Tf) demark the arcade syncytia of the gymnostom (underlain

CA). BL - pharyngeal basal lamina, CR- circumpharyngeal ring, P - pharynx. Bar $=5 \mu \mathrm{m}$; Fig. 10. Serial longitudinal section (continuation ventrodorsally from the level seen in Fig. 9), showing well developed anterior region of muscle cells ( $\mathrm{Mu}$ ) and their extension into circumpharyngeal ring $(\mathrm{CR})$. $\mathrm{BL}$ - pharyngeal basal lamina, $\mathrm{CP}$ - pharyngeal cuticle. Bar $=5 \mu \mathrm{m}$; Fig. 11. Longitudinal semithin section (ventrodorsal view) through the peripheral part of the buccal capsule. $\mathrm{CB}$ - body cuticle, $\mathrm{CA}$ - circumoral cylinder, $\mathrm{CR}$ - circumpharyngeal ring. $\mathrm{Bar}=24 \mu \mathrm{m}$; Fig. 12. Longitudinal ultrathin section following the level seen in Fig. 11. Note infoldings of the basal plasma membrane (BM) of the circumpharyngeal ring $(\mathrm{CR})$ into the anterior pharynx. Bar $=2.5 \mu \mathrm{m}$. 

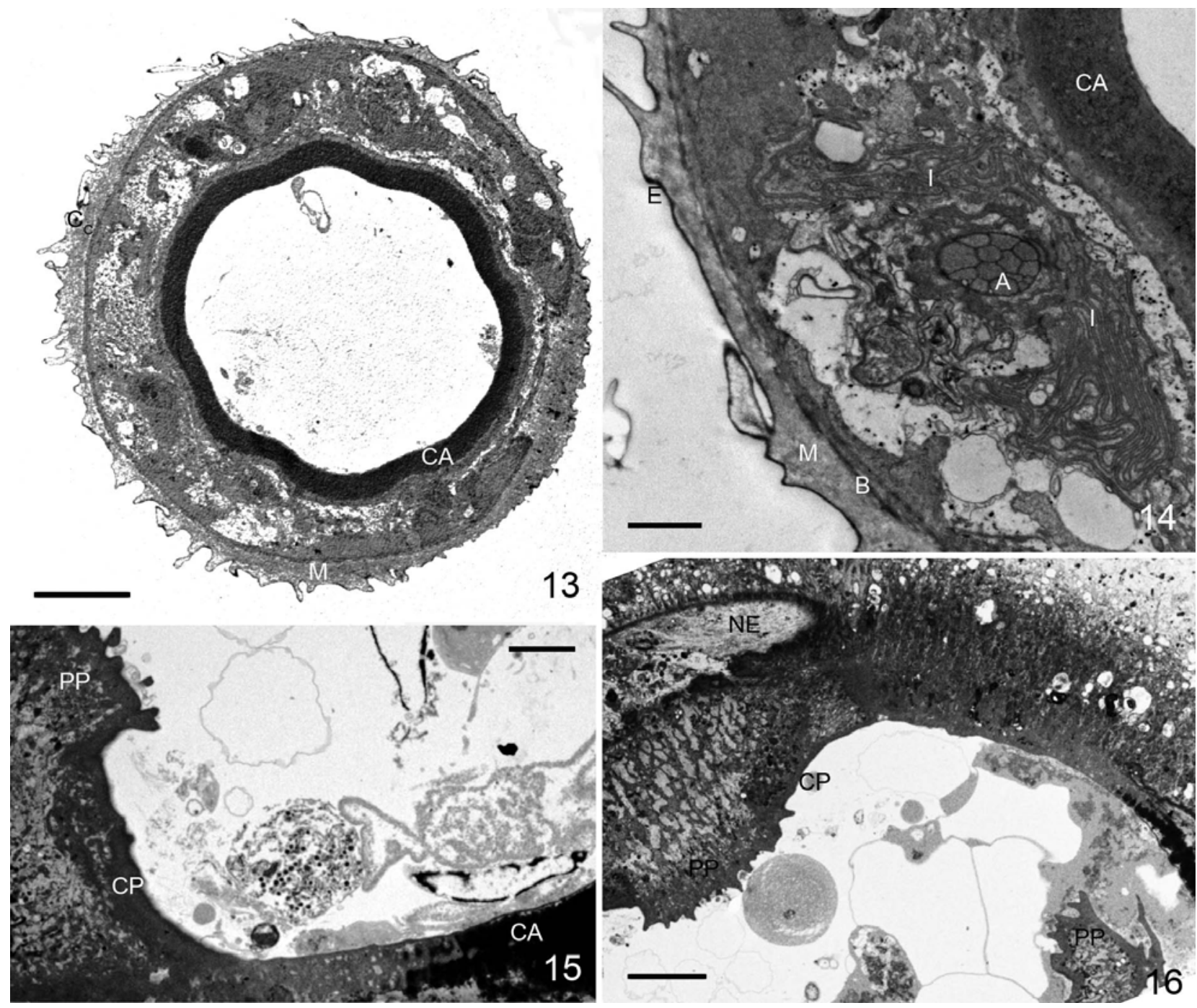

Fig. 13. Cross ultrathin section of the transition zone between cheilostom and gymnostom showing cephalic cuticle with prominent median layer (M). CA-circumoral cylinder. Bar $=10 \mu \mathrm{m}$; Fig. 14. Cross section through lateral amphid (A) in the vicinity of the gymnostom. Note a complex system of membrane infoldings (I). B- basal layer of the cephalic cuticle, CA- circumoral cylinder, E- epicuticle, M- median layer of the cephalic cuticle. Bar $=2 \mu \mathrm{m}$; Fig. 15 . Cross section $(14 \mu \mathrm{m}$ posteriorly from the anerior cheilostom) shows the first projections of the pharynx (PP) protruding into gymnostom. $\mathrm{CP}$ - pharyngeal cuticle, $\mathrm{CA}$ - circumoral cylinder. $\mathrm{Bar}=2 \mu \mathrm{m}$; Fig. 16 . Cross section of the gymnostom $(16 \mu \mathrm{m}$ posteriorly from the anerior cheilostom) shows the two pharyngeal projections (PP). $\mathrm{CP}-$ pharyngeal cuticle. Bar $=5 \mu \mathrm{m}$.

ginal cells. The cephalic cuticle of $A$. crassus makes a direct contact with the pharyngeal cuticle at the base of the circumoral cylinder (Figs. 5, 7, 9, 10). The circumoral cylinder is situated on the circumpharyngeal ring composed of anterior projections of pharyngeal muscular and marginal cells. This circumpharyngeal ring is rich in mitochondria and tonofibrils. It is partly delimited by the pharyngeal basal lamina (Figs. 9, 10). At the periphery of the pharynx (Fig. 11), numerous interdigitations of the basal lamina of the circumpharyngeal ring connect the region with the anterior pharynx (Fig. 12).

The cheilostom has a circular shape in cross sections and is surrounded by numerous neurons and specialized nerve endings or interneurons of the lip region (Figs. 13, 14). The tubular amphidial canal contains 14 closely packed dendritic processes (Fig. 14).
Three projections of the pharynx were observed occasionally in the serial cross sections of $A$. crassus gymnostom. Initially, a single projection of pharyngeal lobe appears in the dorsal sector of the worm (some $14 \mu \mathrm{m}$ posteriorly from the anterior cheilostom) (Fig. 15). This projection is covered by a denser pharyngeal cuticle, and has a close contact with the underlain neural elements (Fig. 16). At the same level, the circumoral cylinder is gradually transformed into less complete ring of components of pharyngeal marginal cells, externally covered by pharyngeal cuticle.

A triangular impression of the buccal capsule is conveyed already $19 \mu \mathrm{m}$ from the anterior cheilostom due to the two pharyngeal projections situated within the gymnostom (Fig. 17). Each projection contains numerous dense granules (Fig. 18). 

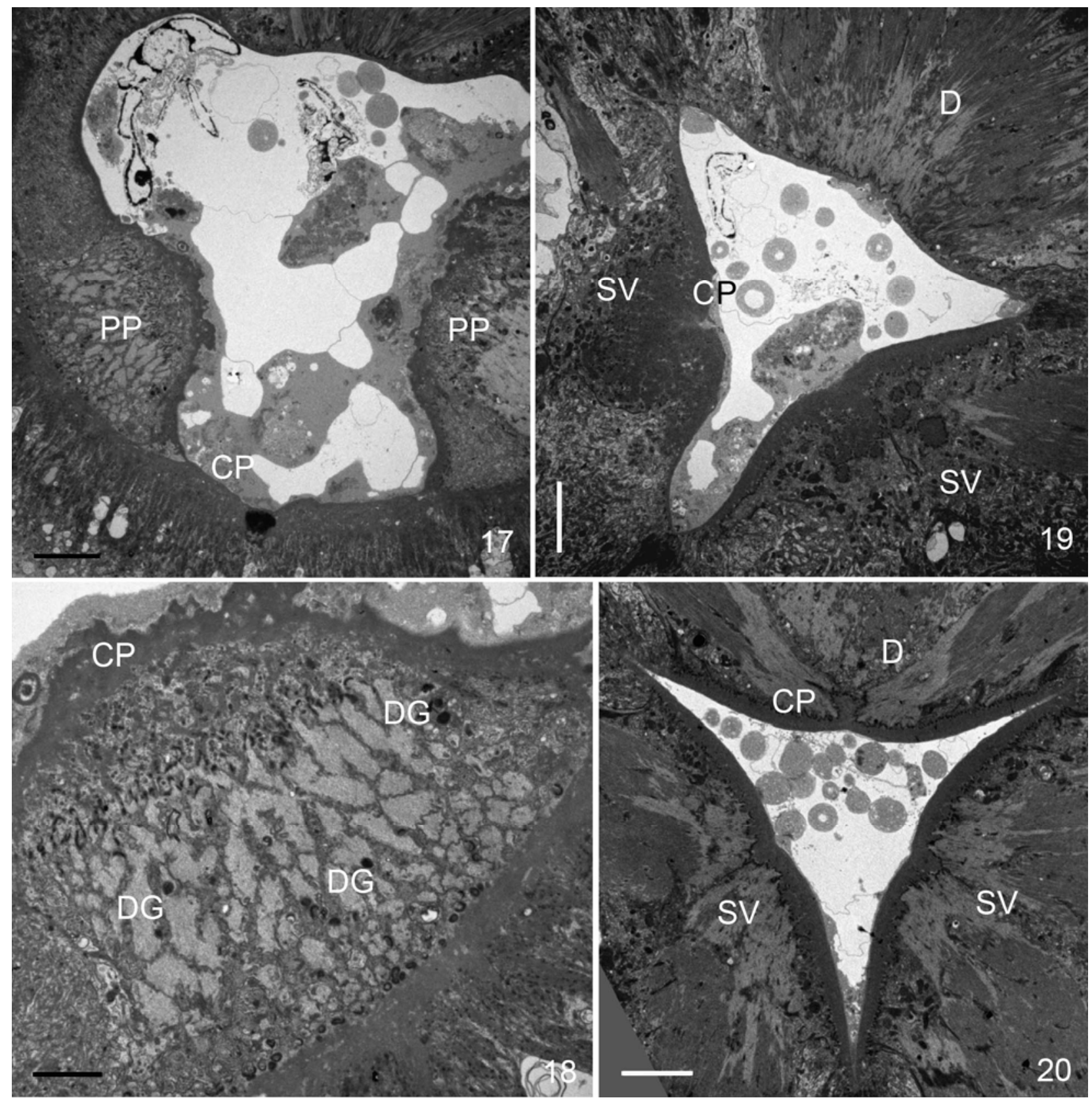

Fig. 17. The two pharyngeal projections (PP) in cross sections some $19 \mu \mathrm{m}$ posteriorly from the anerior cheilostom. $\mathrm{CP}-$ pharyngeal cuticle. Bar $=$ $5 \mu \mathrm{m}$; Fig. 18. Detail of the pharyngeal projection seen in Fig. 17. CP-pharyngeal cuticle, DG - dense granules. Bar $=2 \mu$ m; Fig. 19. Triradiate shape of stegostom as shown in cross sections $23 \mu \mathrm{m}$ posteriorly from the anerior cheilostom. CP-pharyngeal cuticle, D - dorsal side of the pharynx, SV - subventral side of the pharynx. Bar $=5 \mu \mathrm{m}$; Fig. 20. Typical triradiate shape of the stegostom is present in cross sections $25 \mu \mathrm{m}$ posteriorly from the anerior cheilostom. $\mathrm{CP}-$ pharyngeal cuticle, $\mathrm{D}$ - dorsal side of the pharynx, $\mathrm{SV}$ - subventral side of the pharynx. Bar $=5 \mu \mathrm{m}$

The shape of the buccal capsule is changed to triradiate in transverse sections of stegostom some $23 \mu \mathrm{m}$ posteriorly from anterior cheilostom (Fig. 19). At this level, small bottoms of pharyngeal cuticle are situated in the centre of each subventral region. The triradiate shape typical of the pharynx was observed at the base of stegostom, approximately $25 \mu \mathrm{m}$ posteriorly from the anterior cheilostom (Fig. 20).

\section{Discussion}

The buccal capsule of nematodes is a functional unit of the anterior digestive tract covering the region between the mouth opening and the proximal end of the pharynx (Dick \& Wright, 1973). It is characterized by great variability in its shape and structure, reflecting the range and variety of feeding of the individual nematode group (Wright, 1976; 
Gibbons, 2002). Therefore, the buccal capsule has been extensively used as a character in taxonomic and phylogenetic studies of nematodes (Bird \& Bird, 1991; Moravec, 2007; Baldwin et al., 2004; Bumbarger et al., 2006; Ragsdale et al., 2008).

Results of the present study are congruent with the findings that $A$. crassus has the small circular mouth aperture surrounded by 4 dorso- and ventrolateral cephalic papillae as well as 2 small lateral amphids, and the anterior rim of the buccal capsule bears one row of 22, 24, 26 or 28 circumoral teeth (Taraschewski et al., 1987). The buccal capsule of spirurine nematodes parasitizing fishes is frequently provided with well-developed stoma and various sclerotized formations as plates, teeth or spines (Moravec, 2007; Chitwood, 1950; Fagerholm, 1982). Our ultrastructural investigations reveal the presence of a dense circumoral cylinder situated mainly in gymnostom and representing the most prominent part of the buccal capsule of $A$. crassus. Similar structure has been reported only in the cephalic cuticle of the adult blood-feeding nematode Nippostrongylus brasiliensis (Trichostrongyloidea) (Wright, 1976; Wright, 1975). The circumoral cylinder with fingerlike extentions at the anterior edges is supposed to prevent distortions of the cephalic cuticle during feeding, as anterior sense organs and their dendritic processes are present in its close vicinity. This cylinder may be structurally and/or functionally related to the dense component of the supporting struts in the middle zone of body cuticle of some nematodes (Lee, 1965; Wright \& Hope, 1968).

Sclerotized buccal capsule has been reported also in members of Skrjabillanidae, but not in other dracunculoids (Moravec, 1998). The lack of ultrastructural data, however, does not allow for more detailed comparison of ultrastructural features of the buccal capsule within spirurid nematodes. The presence of a sclerotized buccal capsule in Anguillicoloidae and Skrjabillanidae, but not in other dracunculoids, is in good correlation with molecular studies, which suggest exclusion of $A$. crassus from the the Dracunculoidea (Wijová et al., 2006), and support the existence of an independent family Skrjabillanidae within the Dracunculoidea as suggested earlier (Moravec, 1998; Ivashkin et al., 1971).

Other remarkable feature of the buccal capsule is the presence of 6 slightly elevated rounded lobes protruding into the buccal cavity of $A$. crassus (Taraschewski et al., 1987). Our observations have revealed only 3 rounded pharyngeal lobes within the buccal capsule of $A$. crassus females. In our opinion, the presence/absence of the pharyngeal lobes inside the buccal capsule of $A$. crassus may be related either to the developmental stages of the worms or to the functional status of the pharynx during fixation (contracted or relaxed). Our suggestion relates to the fact, that the buccal capsule of the third-stage larva of Nippostrongylus contains three long pharyngeal processes, which are absent in the adults (Lee, 1968). The possibility cannot be exluded, that younger specimens of $A$. crassus may have pharyngeal processes inside the buccal cavity similarly as do larval stages of Nippostrongylus. Further detailed stu- dies of cephalic end of various developmental stages of $A$. crassus might help to elucidate this point.

Results of the present study indicate that the cephalic cuticle of $A$. crassus differs markedly from the pharyngeal cuticle (Bruňanská et al., 2007). This finding corroborates the earlier studies on ultrastrucure of nematode cephalic cuticle (Dick \& Wright, 1973; Wright, 1976; Wright, 1981).

The ultrastructural composition of the circumpharyngeal ring at the base of the circumoral cylinder in A. crassus is similar to that of the hypodermis (=epidermis) of the body wall (Taraschewski et al., 1988). This structural similarity may be associated with the position of the marginal cells (under the pharyngeal cuticle) and position of syncytial epidermis (under the body cuticle) in the worm. Thus, the marginal cells of pharynx may have similar function as the body epidermis in A. crassus. It is noteworthy that circumpharyngeal ring is positioned to form a framework that guides the circumoral cylinder in $A$. crassus, similarly as the hypodermal (=epidermal) cells form a lining that guides the protrusible stylet in Tylenchomorpha (Baldwin \& Ragsdale, 2008). Tonofilaments of the circumoral epidermis of $A$. crassus may serve in reinforcement during muscle action as suggested for $N$. brasiliensis (Wright, 1976).

Results of the present investigation provide also evidence that the cuticle in the head region in $A$. crassus differs from the cuticle of other spirurid nematodes studied to date. This fact may support exclusion of $A$. crassus from the the Dracunculoidea as suggested by molecular studies (Wijová et al., 2006). Only further detailed electronmicroscopical studies of other spirurids may contribute to better understanding of structural patterns and their possible implications for nematode phylogeny.

\section{Acknowledgements}

We are grateful for the technical assistance of Gunilla Henriksson and Esa Numellin, Department of Biology, Åbo Akademi University, Finland, as well as the staff of the Laboratory of Electron Microscopy of the Institute of Parasitology AS CR, České Budějovice, Czech Republic. This study was supported by the Grant Agency of the Czech Republic (project No. 524/06/0170), grants from Finnish and Czech Academies of Sciences (bilateral collaboration), and the the Grant Agency of the Slovak Republic VEGA (project no. 2/0018/08).

\section{References}

BAldwin, J. G., Ragsdale, E. (2008): Plant parasitism evolution of new utensils for eating vegan. In Arlington: 83rd Ann Meet Am Soc Parasitol, p. 36.

Baldwin, J. G., Ragsdale, E. J., Bumbarger, D. (2004): Revised hypotheses for phylogenetic homology of the stomatostylet. Nematology, 6: 623 - 632

Bumbarger, D. J., Crum, J., Ellisman, M. H, Baldwin, J. G. (2006): Three-dimensional reconstruction of the nose 
epidermal cells in the microbial feeding nematode, Acrobeles complexus (Nematoda: Rhabditida). J. Morphol., 267: $1257-1272$

Chitwood, B. G. (1950): An outline classification of the Nematoda. In: Chitwood, B. G, Chitwood, M. M. (Eds) Introduction to nematology. Baltimore: University Park Press: $1-30$.

BAUER, O. N. (1998): A new parasitic nematode from the genus Anguillicola (Dracunculoidea: Anguillicolidae) in Palaearctic fish. Parazitologiya, 32: $59-65$

BIRD, A. F., BIRD, J. (1991): The structure of nematodes, Academic Press, Inc.: San Diego

BruŇAnskÁ, M., FAgerholm, H. P., Moravec, F. (2007): Structure of the pharynx in the adult nematode Anguillicoloides crassus (Nematoda: Rhabditida). J. Parasitol., 93: $1017-1028$

De Ley, P., Van de Velde, M. C., Mounport, D., BAujard, P., CoOmans, A. (1995): Ultrastructure of the stoma in Cephalobidae, Panagrolaimidae and Rhabditidae, with a proposal for a revised stoma terminology in Rhabditida (Nematoda). Nematologica, 41: 153 - 182

Dick, T. A., Wright, K. A. (1973): The ultrastructure of the cuticle of the nematode Syphacia obvelata (Rudolphi, 1802). II. Modifications of the cuticle in the head end. Can. J. Zool., 51: $197-202$

DIDŽIULIS, V. (2006): NOBANIS - Invasive Alien Species Fact Sheet - Anguillicola crassus. Online Database of the North European and Baltic Network on Invasive Alien Species - NOBANIS www.nobanis.org, Date of access 16/7/2008.

FAgerholm, H. P. (1982): Parasites of fish in Finland. VI. Nematodes. Acta Acad. Aboen., Ser. B, Math. \& Physica, 40: 1 - 128 .

GiBbons, L. M. (2002): General organisation. In: Lee DL, editor. The biology of nematodes. London: Taylor and Francis: $31-59$.

Ivashkin, V. M., Sobolev, A. A., Khromova, L. A. (1971): Camallanids as causative agents of humans and animals. In Osnovy nematodologii 22, Nauka: Moskva (in Russian).

Kennedy, C. R., Di Cave, D., Berrilli, F., Orecchia, P. (1997): Composition and structure of helminth communities in eel Anguilla anguilla from Italian coastal lagoons. $J$. Helminthol., 71: 35 - 40

KIRK, R. S. (2003): The impact of Anguillicola crassus on European eels. Fisheries Manag. Ecol., 10: 385 - 394

KNOPF, K. (2006): The swim bladder nematode Anguillicola crassus in the European eel Anguilla anguilla and the Japanese eel Anguilla japonica: differences in susceptibility and immunity between a recently colonized host and the original host. J. Helminthol., 80: $129-136$

LAmah, T., Franz, M., MehlHORn, H., TARAscheWsKi, H. (1990): Comparison of Philometra ovata Zeder, 1803 and Anguillicola crassus Kuwahara et al. 1974 (Nematodes, Dracunculoidea) - a light and electron-microscopic studies. Ann. Sci. Nat. Zool. Biol. Anim., 11: 123 - 133

LEE, D. L. (1965): The cuticle of adult Nippostrongylus brasiliensis. Parasitology, 55: 173 - 181
LEE, D. L. (1968): The ultrastructure of the alimentary tract of the skin-penetrating larva of Nippostrongylus brasiliensis (Nematoda). J. Zool. Lond., 154: 9 - 18

Maítlo, P. A., Vich, M. A., SAlvadó, H., MarquÉS, A., Gracia, M. P. (2005): Parasites of Anguilla anguilla (L.) from three coastal lagoons of the River Ebro delta (Western Mediterranean). Acta Parasitol., 50: 156 - 160

Moravec, F., ŠKoríkovÁ, B. (1998): Amphibians and larvae of aquatic insects as new paratenic hosts of Anguillicola crassus (Nematoda: Dracunculoidea), a swimbladder parasite of eels. Dis. Aquat. Org., 34: 217 - 222

MORAVEC, F. (2006): Dracunculoid and anguillicoloid nematodes parasitic in vertebrates. Academia: Praha.

MorAVEC, F. (1998): Nematodes of freshwater fishes of the Neotropical region. Academia: Praha.

MoRAVEC, F. (2007): Some aspects of the taxonomy and biology of adult spirurine nematodes parasitic in fishes: a review. Folia Parasitol., 54: 239 - 257

MORAVEC, F. (1992): Spreading of the nematode Anguillicola crassus (Dracunculoidea) among eel populations in Europe. Folia Parasitol., 39: 247 - 248

Ragsdale, E. J., Crum, J., Ellisman, M. H., Baldwin, J. G. (2008): Phylogenetic implications of three dimensional reconstruction of the stomatostylet and anterior epidermis in Aphenchus avenae. J. Morphol., 269: 1181 - 1196

Sasal, P., TARaschewski, H., Valade, P., Grondin, H., Wielgoss, S., MoraveC, F. (2008): Parasite communities in eels of the Island of Reunion (Indian Ocean): a lesson in parasite introduction. Parasitol. Res., 102: 1343 - 1350

TARASCHEWsKi, H., BoOMKER, J., KNOPF, K., MORAVEC, F. (2005): Anguillicola papernai (Nematoda: Anguillicolidae) and other helminths parasitizing the African longfin eel Anguilla mossambica. Dis. Aquat. Org., 63: 185 - 195.

TARASCHEWSKi, H., MoraveC, F., LAMAH, T., ANDERS, K. 1987: Distribution and morphology of two helminths recently introduced into European eel populations: Anguillicola crassus (Nematoda, Dracunculoidea) and Paratenuisentis ambiguus (Acanthocephala, Tenuisentidae). Dis. Aquat. Org., 3: $167-176$.

TARASCHEWSKI, H., RENNER, C., MEHLHORN, H. (1988): Treatment of fish parasites. 3. Effects of levamisole $\mathrm{HCl}$, metrifonate, fenbendazole, mebendazole, and ivermectin on Anguillicola crassus (nematodes) pathogenic in the air bladder of eels. Parasitol. Res., 74: 281 - 289

TARASCHEWSKI, H.: Host and parasites as aliens. $J$. Helminthol., 80: $99-128$

WiJovÁ, M., Moravec, F., HorÁK, A., LUKEŠ, J. (2006): Evolutionary relationships of Spirurina (Nematoda: Chromadorea: Rhabditida) with special emphasis on dracunculoid nematodes inferred from SSU rRNA gene sequences. Int. J. Parasitol.. 36: 1067 - 1075

Wright, K. A., HOPE, W.D. (1968): Elaborations of the cuticle of Acanthonchus duplicatus Wieser, 1959 (Nematoda: Cyatholaimidae) as revealed by light and electron microscopy. Can. J. Zool., 46: $1005-1011$

Wright, K. A., ThOMSON, J. N. (1981): The buccal capsule of Caenorhabditis elegans (Nematoda: Rhabditoidea): an ultrastructural study. Can. J. Zool., 59: 1952 - 1961 
Wright, K. A. (1975): Cephalic sense organs of the rat hookworm, Nippostrongylus brasiliensis - form and function. Can. J. Zool., 53: 1131 - 1146

Wright, K. A. (1976): Functional organization of the nematode's head. In: CrOLL, N. A. (Ed) The organization

RECEIVED JANUARY 12, 2010 of nematodes. London: Academic Press: $71-105$.

WÜRTZ, J., TARASCHEWSKI, H. (2000): Histopathological changes in the swimbladder wall of the European eel Anguilla anguilla due to infections with Anguillicola crassus. Dis. Aquat. Org., 39: 121 - 134

ACCEPTED MAY 7, 2010 